\title{
The analytic utility of distinguishing fighting from dying-ERRATUM
}

\author{
Ian Grant Hansen
}

\section{Erratum}

Cite this article: Hansen IG. (2019) The analytic utility of distinguishing fighting from dying-ERRATUM. Behavioral and Brain Sciences 42, e34, 1. doi:10.1017/ S0140525X19000293

https://doi.org/10.1017/S0140525X18001772. Published by Cambridge University Press, 27 December 2018

In the originally-released pdf, the word "and" within quotation marks was accidentally and erroneously inserted, contrary to the instructions of the author, before the final word of the abstract in the commentary by Hansen (2018) on the target article by Whitehouse (2018).

The abstract should read as follows.

Abstract

Fighting and dying, or what Whitehouse calls "out-group hostility" and "extreme selfsacrifice," are not conceptually overlapping, but in fact are highly distinguishable, both theoretically and empirically. I present empirical evidence from a reanalysis of Ginges et al. (2009, Study 4), demonstrating the potentially inverse relationship between "parochial hostility" fighting and "sacrificial altruism" - dying.

We regret the error and we have corrected the abstract online.

In addition, there is an error in the note to Table 1 in the commentary. The note should read as follows:

${ }^{\dagger} p<.10^{*} p<.05^{* *} p<.01{ }^{* *} p<.001$

The table with the corrected note follows:

Table 1. (Hansen) Odds of blaming people of other religions for the world's problems (parochial hostility) as predicted by sacrificial altruism and other religiosity measures

\begin{tabular}{|c|c|c|c|c|c|}
\hline Predictor & Model & Odds ratio & $95 \% \mathrm{Cl}$ & Wald & $\begin{array}{l}\text { Odds of supporting parochial } \\
\text { hostility, given affirmative } \\
\text { response to predictor }\end{array}$ \\
\hline Sacrificial altruism & Independent & 0.82 & $0.69-0.96$ & $6.10^{\star}$ & $1.23: 1$ against \\
\hline Belief in God & Zero order & 0.54 & $0.45-0.64$ & $47.07^{\star \star \star}$ & $1.87: 1$ against \\
\hline Regular prayer & Independent & 0.54 & $0.45-0.64$ & $49.76^{\star \star \star}$ & $1.86: 1$ against \\
\hline \multirow[t]{2}{*}{ Afterlife belief } & Zero order & 0.91 & $0.79-1.04$ & 1.88 & 1.10:1 against \\
\hline & Independent & 0.98 & $0.85-1.13$ & 0.09 & $1.02: 1$ against \\
\hline Regular religious attendance & Zero order & 0.88 & $0.77-1.01$ & $3.38^{\dagger}$ & $1.14: 1$ against \\
\hline
\end{tabular}

${ }^{\dagger} p<.10 .{ }^{*} p<.05 .{ }^{* \star} p<.01 .{ }^{\star \star *} p<.001$.

\section{References}

[The letters "a" and " $r$ " before author's initials stand for target article and response references, respectively] 